\title{
MODERN METHODS OF COMPLEX CORRECTION OF PSYCHOSOMATIC DISORDERS IN PATIENTS WITH EXTERNAL GENITAL ENDOMETRIOSIS
}

10.36740/WLek202012112

\author{
Nikolay A. Shcherbina, Liliya V Potapova, Irina N. Shcherbina, Oksana P. Lipko , Olga V. Mertsalova, \\ Anastasiia A. Chekhunova \\ KHARKIV NATIONAL MEDICAL UNIVERSITY, KHARKIV, UKRAINE
}

\begin{abstract}
The aim: About 10\% of socially active women of reproductive age suffer from endometriosis, is determined by the frequent occurrence of menstrual and reproductive functions disorders, and pelvic pain syndrome in patients. The difficulties of therapeutic treatment of chronic pain syndrome in external genital endometriosis (EGE) are associated with polymorphism of pain mechanisms, and delayed diagnosis and treatment. The aim of the study is to improve the effectiveness of the treatment of external genital endometriosis. Material and methods: We examined 60 female patients of reproductive age, 40 - with histologically verified diagnosis of external genital endometriosis and 20 healthy women. We used the following methods of examination: general clinical, instrumental, endoscopic, morphological, the Visual Analogue Scale (VAS) to quantify pain, the Beck Depression Scale and the SF-36 questionnaire.

Results: Before the treatment of patients with EGE, VAS scale scores indicated pain in 100\% of patients, the indicators of depression and level of anxiety go beyond the normative. The results of the pre-treatment questionnaire indicated lower quality of life scores on the scales of physical and mental health components. As a result of treatment there was significant decrease in the manifestations of pain, depression and anxiety, with women receiving complex therapy (hormone therapy got antidepressants and non-drug correction methods).

Conclusions: Chronic pelvic pain syndrome associated with EGE and accompanied by an unfavorable psychological state, depressive states, anxiety symptoms, and psychosomatic disorders. New approaches to the treatment of clinical manifestations of EGE are needed, taking into account patients' psycho-emotional status and the life quality analysis. We pathogenetically justified the use of drugs that affect the psychosomatic status of patients with EGE and showed that they could significantly improve the quality of life.
\end{abstract}

KEY WORDS: Genital endometriosis, pelvic pain syndrome, depression, anxiety, life quality

Wiad Lek. 2020;73(12 p. I):2623-9626

\section{INTRODUCTION}

The problem of genital endometriosis has recently become particularly acute due to the increasing frequency of this pathology, and the introduction of modern methods of its diagnosis and treatment into clinical practice. The importance of the endometriosis problem is determined by the frequent occurrence of menstrual and reproductive functions disorders, and pelvic pain syndrome in patients. About $10 \%$ of socially active women of reproductive age suffer from endometriosis, the incidence of pelvic pain in endometriosis is from 26 to $80 \%$. The difficulties of therapeutic treatment of chronic pain syndrome in external genital endometriosis (EGE) are associated with polymorphism of pain mechanisms, and delayed diagnosis and treatment. With regard to the mechanisms underlying pain caused by endometriosis, scientists suggested that the pathological innervation of ectopic foci of the endometrium was the cause of the generation of pelvic pain $[1,2]$.

In most patients, the pain is accompanied by general weakness, anxiety, fear, excitability, emotional lability, scattered attention, memory impairment, and other psycho-asthenic manifestations that disturb every second patient and result in a significant decrease of life quality $[3,4]$.

Based on the recommendations of modern medical forums and the existing concept of unity of the mental and somatic, a long-term adverse condition of a women can form subdepressive changes, neuroses, psychopathies, which in turn create the basis for the development of psychosomatic changes in women [4] .

Taking into account the high incidence of depressive states in this category of patients, scientists suggested using a variety of psychometric scales to evaluate the clinical manifestations of the disease to assess depression and anxiety. The study conducted by Laganà et al., researched the quality of life (QL), negative emotions such as anger, anxiety, and depression, and possible psychopathological comorbidity in a sample of 166 women with endometriosis. Patients were offered self-assessment tools such as a symptom checklist-90-R, anger expression rating scale, depression scale, and quality of life index. The results showed that somatization, depression, sensitivity and phobic anxiety were higher in these patients than in women without endometriosis. In addition, the same authors found that women with endometriosis were characterized by high 
levels of anxiety and a significant decrease in quality of life [5]. Chen et al. used the Taiwan National Health Insurance Research Database (NHIRD) with a longitudinal study design to identify women with endometriosis who were diagnosed with depression or anxiety disorders through collaboration with psychiatrists. They found that endometriosis was associated with an increased risk of depression and anxiety disorders [6]. Therefore, we think that in most cases patient's management should be conducted on an interdisciplinary basis, with the involvement of specialists of psychotherapeutic profile taking into account their psychosomatic disorders.

Thus, complex and unresolved problems include the definition of the role of psychological factors in the pathogenesis of endometriosis, because there is no clear relationship between endometriosis and psychosomatic disorders, and the impact of this disease on the quality of life (physical, social well-being) and strategies for managing such patients.

\section{THE AIM}

The aim of the study is to improve the effectiveness of external genital endometriosis treatment by developing methods of complex correction, taking into account psychosomatic disorders in patients.

\section{MATERIALS AND METHODS}

We examined 60 female patients of reproductive age; their mean age was $29.3 \pm 2.3$ years. The group A consisted of 40 patients suffering from chronic pelvic pain with histologically verified diagnosis of external genital endometriosis. The group B consisted of 20 healthy women. The concept of pelvic pain includes the most common symptoms: dysmenorrhea, dyspareunia and non-cyclic pelvic pain.

In the work we used the following complex methods of examination: general clinical, instrumental, endoscopic, morphological. To be included in the study the patients should have EGE with pelvic pain, lasting more than 6 months. Exclusion criteria for the study: genital inflammation, cancer, severe somatic extragenital pathology. All patients signed a written informed consent to participate in the study.

Statistical analysis was performed using the Microsoft Excel data analysis package and Biostat using the Student test. The study results were considered reliable at $(\mathrm{p} \leq 0.05)$.

We used the Visual Analogue Scale (VAS) to quantify pain: the starting point of the line indicates no pain (0), the end point shows intolerable pain [7]. A reactive and personality anxiety assessment was conducted using the Spielberger-Hanin questionnaire (1976). If a patient had up to 30 points it was low anxiety; $31-44$ points - moderate anxiety; 45 points or more - expressed anxiety. The Beck Depression Inventory (1961) was used to evaluate patients according to the Beck Depression Scale: up to 9 points no depressive symptoms; $10-15$ points - mild depression (sub-depression); 16-19 points - moderate depression; 2029 points - severe depression. The SF-36 questionnaire was used to assess the quality of life, which allowed analyzing 4 components of physical health and 4 components of mental health [8] . The scores on each scale range from 0 to 100 points, where 100 points is full health. All patients were asked to use scales and questionnaires before treatment and 1 month after initiation of treatment.

\section{RESULTS}

The main reasons for the treatment of patients were complaints of pain in the lower abdomen in 18 (45\%) women, pelvic pain, not associated with menstruation or intercourse in $10(25 \%)$ patients, dyspareunia was noted in 13 (32,5\%) women. Complaints related to dysmenorrhea accompanied by headache and dizziness worried $8(20 \%)$ patients. In most patients, the pain was accompanied by general weakness, anxiety, fear, excitability, emotional lability, distracted attention, memory impairment, sleep disturbances and psycho-asthenic manifestations. 25 (62.5\%) women reported increased irritability, depressed mood, decreased performance and other psycho-emotional disorders.

Analysis of anamnestic data on menstrual function in examined women showed that $31(77.5 \%)$ patients had their first menstruation at the age of 10-11 years. It was noted that in $12(30 \%)$ patients the menstrual cycle was established in the period from 6 months to 2 years, indicating the functional inferiority of the various units of the hypothalamus-pituitary-ovarian system. In 20 (50\%) patients, dysmenorrhea occurred with the onset of menarche. In the control group, the average age of menarche onset was $12-13$ years, 16 (80\%) women had menstrual cycles with an average duration of $29.2+1.3$ days which immediately became regular, unlike women with EGE, whose menstrual cycle was mostly short with an average duration of $23+1.5$ days.

Family medical records analysis showed a significantly higher $(p<0.05)$ incidence of gynecological diseases in relatives of patients with EGE, compared with group B women ( $40 \%$ and 5\%, respectively). Thus, according to various authors, the results of genetic studies indicated that the likelihood of endometriosis was 3-10 times higher among relatives of the first hereditary line of women with this disease $[9,10]$.

$4.9+0.7$ years have passed since patients complained of lower abdominal pain. During this time, patients of the main group underwent 2 to 6 courses of anti-inflammatory outpatient treatment, and $12(30 \%)$ received combined oral contraceptives.

All women underwent laparoscopy surgery for EGE. Depending on the type of postoperative conservative therapy, patients were divided into two subgroups: the $1^{\text {st }}$ subgroup included 20 (50\%) patients who received hormone monotherapy for 6 months with progestogens, nortestosterone derivatives; the $2^{\text {nd }}$ subgroup had $20(50 \%)$ patients who in addition to hormone therapy got antidepressants, selective serotonin reuptake blockers with psychotherapeutic non-drug correction methods. Clinical criteria for the effectiveness of treatment were blocking or reducing the intensity of pain, and the absence of relapse. 
Table I. Dynamics of anxiety and depression indicators in the examined patients, in points

\begin{tabular}{|c|c|c|c|c|c|}
\hline \multirow{3}{*}{$\begin{array}{l}\text { Method of } \\
\text { evaluation }\end{array}$} & \multicolumn{4}{|c|}{ Group A } & \multirow{3}{*}{ Group B } \\
\hline & \multirow{2}{*}{$\begin{array}{c}\text { Before treatment } \\
\text { I subgroup }\end{array}$} & \multicolumn{3}{|c|}{ After treatment } & \\
\hline & & II subgroup & I subgroup & II subgroup & \\
\hline Beck Depression Scale & $17.9 \pm 2.43^{*}$ & $16.8 \pm 1.88^{*}$ & $11.51 \pm 1.66^{* *}$ & $7.21 \pm 1.25^{* *}$ & $3.98 \pm 1.34$ \\
\hline $\begin{array}{l}\text { Spielberger-Hanin test } \\
\text { Reactive Anxiety }\end{array}$ & $40.8 \pm 2.37^{*}$ & $39.7 \pm 2.42^{*}$ & $34.3 \pm 1.72^{* *}$ & $28.9 \pm 2.68^{* *}$ & $25.4 \pm 1.28$ \\
\hline Personal anxiety & $48.2 \pm 2.65^{*}$ & $49.3 \pm 4.21 *$ & $38.9 \pm 1.83^{* *}$ & $33.2 \pm 2.35^{* *}$ & $24.9 \pm 1.87$ \\
\hline
\end{tabular}

Note: ${ }^{*}-p \leq 0.05$ statistically significant differences before and after treatment.

** $-p<0.05$ compared with the group $B$.

Table II. Comparison of the quality of life indicators in the main and control group

\begin{tabular}{ccc}
\hline «SF-36» Scales & Group A & Group B \\
\hline Physical Functioning & $68.64 \pm 6.5^{*}$ & $92.53 \pm 5.4$ \\
\hline Role Functioning caused by Physical Condition & $57.39 \pm 5.6^{*}$ & $81.26 \pm 4.8$ \\
\hline Intensity of pain & $47.74 \pm 10.1^{*}$ & $73.74 \pm 7.5$ \\
\hline Overall Health Condition & $53.80 \pm 3.3^{*}$ & $66.58 \pm 2.3$ \\
\hline Lifetime Activity & $44.39 \pm 5.3^{*}$ & $59.37 \pm 3.2$ \\
\hline Social functioning & $54.28 \pm 4.7^{*}$ & $71.24 \pm 3.4$ \\
\hline Role Functioning caused by Emotional Condition & $47.76 \pm 6.2^{*}$ & $70.93 \pm 4.9$ \\
\hline Mental health & $35.43 \pm 1.0^{*}$ & $31.52 \pm 0.8$ \\
\hline
\end{tabular}

Note: ${ }^{*}-p \leq 0.05$ statistically significant differences compared to group B

Table III. Results of dynamic monitoring of quality of life in women with EGE

\begin{tabular}{|c|c|c|c|c|c|}
\hline \multirow{3}{*}{ «SF-36» scales } & \multicolumn{4}{|c|}{ Group A } & \multirow{3}{*}{ Group B } \\
\hline & \multicolumn{2}{|c|}{ I subgroup } & \multicolumn{2}{|c|}{ II subgroup } & \\
\hline & $\begin{array}{c}\text { Before } \\
\text { treatment }\end{array}$ & $\begin{array}{c}\text { After } \\
\text { treatment }\end{array}$ & $\begin{array}{c}\text { Before } \\
\text { treatment }\end{array}$ & $\begin{array}{c}\text { After } \\
\text { treatment }\end{array}$ & \\
\hline Physical Functioning & $78.08 \pm 0.8^{*}$ & $81.41 \pm 0.8^{* *}$ & $77.95 \pm 2.1^{*}$ & $89.35 \pm 2.9^{* *}$ & $90.28 \pm 0.9$ \\
\hline Role Functioning caused by Physical Condition & $55.61 \pm 4.6^{*}$ & $73.97 \pm 4.2^{* *}$ & $69 \pm 4.6^{*}$ & $83.42 \pm 2.4^{* *}$ & $86.14 \pm 3.7$ \\
\hline Intensity of pain & $54.12 \pm 7.3^{*}$ & $79.67 \pm 4.6^{* *}$ & $50.95 \pm 8.7^{*}$ & $81 \pm 6.6^{* *}$ & $83.75 \pm 5.9$ \\
\hline Overall Health Condition & $52.80 \pm 2.0^{*}$ & $61.5 \pm 2.4^{* *}$ & $49.48 \pm 2.4^{*}$ & $62.9 \pm 2.9 * *$ & $75.28 \pm 5.1$ \\
\hline Lifetime Activity & $44.86 \pm 2.0^{*}$ & $56.28 \pm 2.5^{* *}$ & $48.08 \pm 3.5^{*}$ & $65.17 \pm 2.17^{* *}$ & $78.17 \pm 8.4$ \\
\hline Social functioning & $61.45 \pm 3.6^{*}$ & $77.27 \pm 2.1^{* *}$ & $66.95 \pm 3.8^{*}$ & $78.09 \pm 1.1^{* *}$ & $89.19 \pm 4.8$ \\
\hline Role Functioning caused by Emotional Condition & $51.38 \pm 4.2^{*}$ & $72.63 \pm 4.6^{* *}$ & $57.27 \pm 4.6^{*}$ & $82.64 \pm 3.7^{* *}$ & $77.78 \pm 5.6$ \\
\hline Mental health & $51.59 \pm 2.1^{*}$ & $62.49 \pm 1.5^{* *}$ & $54.62 \pm 4.0^{*}$ & $76.26 \pm 3.3^{* *}$ & $77.19 \pm 3.1$ \\
\hline
\end{tabular}

Note: ${ }^{*}-p<0.05$ compared with pre-treatment rates;

** $-p<0.05$ compared with the group B.

Before the treatment of patients with EGE, VAS scale scores indicated pain in $100 \%$ of patients (VAS score $6.59+0.36$ ). However, the intensity of pain on the VAS scale in patients was different. The presence of severe pain (VAS from 7 to 10) was indicated by $13(32.5 \%)$ patients, moderate pain (VAS from 3 to 7 ) was noted by 23 (57.5\%) women, and 3 (7.5\%) patients characterized mild pain (VAS from 0 to 3 ). VAS pain intensity rates were significantly higher in the main group than in the control group $(\mathrm{p}<0.05)$. In the course of treatment, pain rates have changed. Thus, after 1 month of therapy in the main group, pain was present in 37 (92.5\%) patients of the $1^{\text {st }}$ subgroup, at the same time in the $2^{\text {nd }}$ subgroup VAS decreased to $2.71+0.22$ points $(\mathrm{p}<0.05)$, and pain intensity was characterized as mild (VAS 0 to 3 ) and moderate (VAS 3 to 7$)$ in $17(85 \%)$ and $3(15 \%)$ patients, respectively.

When assessing baseline anxiety and depression, we received the results presented in Table I.

\section{DISCUSSION}

It should be noted that the results of our study are consistent with the literature on the significant role of the psychosomatic component in the pathogenesis of chronic pelvic pain in external genital endometriosis. Thus, in this category of patients 
the indicators of depression and level of anxiety go beyond the normative. The mean depression in the main group corresponded to mild depression $(17.4+2.2$ Beck), mean reactive anxiety corresponded to $40.3+4.40$ on the Spielberger-Hanin scale, and personal anxiety was $48.8+4,43$ points. As a result of treatment there was a statistically significant decrease in the manifestations of depression and anxiety, with women receiving complex therapy (subgroup 2) experiencing pronounced positive dynamics of the studied indicators.

The results of the pre-treatment questionnaire indicated lower quality of life scores on the scales of physical and mental health components (Table II).

The analysis of life quality assessment results showed that the patients with EGE had statistically significant lower scores for most indicators of the SF36 quality of life scale (Table III). When comparing the dynamics of these indicators before and after complex therapy, we observed a significant increase in quality of life in patients of the $2^{\text {nd }}$ subgroup.

A follow-up examination 12 months after treatment showed complete resolution of pain syndrome in (90.8\%) women of the $2^{\text {nd }}$ subgroup and in $15(75 \%)$ women of the $1^{\text {st }}$ subgroup. We did not fix complaints of dyspareunia, dysmenorrhea and menometrorrhagia after comprehensive treatment. Pain relapse was not observed in any case of the $2^{\text {nd }}$ subgroup patients. On average, the intensity of pain during the observation decreased by 5.4 times compared to the baseline data. On average, 2-3 months after completion of complex therapy, all women who wanted to give birth to a child, did it. Pregnancy occurred in 19 (95\%) women, and $16(80 \%)$ of them gave birth to a child. During the year of observation within a comprehensive correction of recurrent external genital endometriosis, women did not show external genital endometriosis in any case.

\section{CONCLUSIONS}

1. According to recent data, the pathogenesis of endometriosis is multifactorial and psychological factors play an important role in determining the severity of symptoms and the effectiveness of treatment. In $25 \%$ of patients with EGE had chronic pelvic pain syndrome associated with EGE and accompanied by an unfavorable psychological state, depressive states, anxiety symptoms, and psychosomatic disorders.

2. At the present stage, new approaches to the treatment of clinical manifestations of EGE are needed, taking into account patients' psycho-emotional status and the life quality analysis. We pathogenetically justified the use of drugs that affect the psychosomatic status of patients with EGE and showed that they could significantly improve the quality of life.

\section{REFERENCES}

1. Management of patient with endometriosis. Unified clinical protocol of primary, secondary (specialized) and tertiary (highly specialized) medical care, approved by the Order of Ministry of Health of Ukraine №319 from 6 of April 2016.
2. Orazov M.R., Nosenko E.N., Khamoshina M.B., et al.. Evaluation of pain syndrome in patients with endometriosis-associated pelvic pain caused by external genital endometriosis. Obstetrics, Gynecology and Reproduction. 2017; 11:18-22. (in Russian)

3. Adamian L. V., Sonova M. M. et al. Sovremennye metody otsenki kachestva zhizni bolnykh endometriozom [Modern methods in evaluation of the quality of life of patients with endometriosis] Lechashchii vrach Journal. 2018; 11:70-73. (In Russian).

4. Muneyyirci-Delale 0. , Charles C., Sinaii N., et al. Health-related quality of life improvement in women with endometriosis-associated pain during treatment. Fertility and Sterility. 2014;102:e14.

5. Lagana A.S., Condemi I., Retto G. et al. Analysis of psychopathological comorbidity behind the common symptoms and signs of endometriosis. Eur J Obstet Gynecol Reprod Biol. 2015.194:30-3.

6. Chen L.C., Hsu J.W., Huang K.L. et al. Risk of developing major depression and anxiety disorders among women with endometriosis: A longitudinal follow-up study. J Affect Disord. 2016;190:282-285.

7. Novik A. A., Ionova T. I. "Issledovanie kachestva zhizni v meditsine: Uchebnoe posobie" [Studying the quality of patients in medicine: textbook" GEOTAR-MED., Moscow. 2004;304. (In Russian).

8. Moradi M., Parker M., Sneddon A. et al. Impact endometriosis on women's lives: a qualitative study. BMCWomen's Health. 2014;14(1):123

9. Greene A.D., Lang S.A., Kendziorski J.A. et al. Endometriosis: where are we and where are we going? Reproduction. 2016;152:R63-78.

10. Riazi H., Tehranian N., Ziaei S. et al. Clinical diagnosis of pelvic endometriosis: a scoping review. BMCWomen's health. 2015;15:39-39.

This study was supported by Department of Obstetrics and Gynecology №1, Kharkiv National Medical University.

\section{ORCID and contributionship:}

Nikolay A. Shcherbina: 0000-0003-3605-7204 A, B, C, D, E, F

Liliya V Potapova: 0000-0002-2022-5333 ${ }^{A, B, C, D, E, F}$

Irina N. Shcherbina: 0000-0001-7666-8953 ${ }^{A, B, C, D, E, F}$

Oksana P. Lipko: 0000-0001-6462-3563 ${ }^{A, B, C, D, E, F}$

Olga V. Mertsalova: 0000-0001-9967-4918 A, B, C, D, E, F

Anastasiya A. Chekhunova: 0000-0002-6509-5747 ${ }^{A, B, C, D, E, F}$

\section{Conflict of interest:}

The Authors declare no conflict of interest.

\section{CORRESPONDING AUTHOR}

\section{Olga V. Mertsalova}

Kharkiv National Medical University

4 Nauky Avenue, 61022 Kharkiv, Ukraine

tel: +380675773031

e-mail:merts@ukr.net

Received: 31.01 .2020

Accepted: 01.09 .2020

A - Work concept and design, B - Data collection and analysis, C - Responsibility for statistical analysis,

D-Writing the article, $\mathbf{E}$-Critical review, $\mathbf{F}$ - Final approval of the article 